\title{
A RELAÇÃO ENTRE A SOCIEDADE DO HIPERCONSUMO E A HIPERVULNERABILIDADE DO CONSUMIDOR IDOSO: UMA ANÁLISE A PARTIR DO CASO DAS “ALMOFADAS MILAGROSAS”
}

\section{THE RELATIONSHIP BETWEEN THE HYPER-CONSUMER SOCIETY AND THE HYPERVULNERABILITY OF THE ELDERLY CONSUMER:} AN ANALYSIS OF THE CASE OF "MIRACLE PILLOWS"

\section{CARLOS EDUARDO SILVA E SOUZA}

Doutor em Direito pela Faculdade Autônoma de Direito de São Paulo - FADISP (tendo sido aprovado com distinção e louvor em sua defesa de tese), Mestre em Direito Agroambiental pela UFMT - Universidade Federal de Mato Grosso (tendo sido aprovado com louvor em sua defesa de dissertação). Atualmente, é Professor Adjunto dos Cursos de Graduação em Direito e de Mestrado em Direito da Faculdade de Direito da Universidade Federal de Mato Grosso, onde também é Coordenador Titular do Mestrado em Direito, Líder do Grupo de Pesquisa "Direito Civil Contemporâneo" e Coordenador do Laboratório de Direito Civil Contemporâneo.

MARIANA CARVALHO VICTOR COELHO Mestre em Direito pela Faculdade de Direito da Universidade Federal de Mato Grosso. Especialista em Direito Processual Civil pela Fundação Escola Superior do Ministério Público de Mato Grosso (2017). Membro do grupo de pesquisas "Jusclima".

\section{RESUMO}

Objetivo: O presente artigo tem, como objeto, a análise de acórdão proferido pelo 
Tribunal de Justiça do Estado do Rio Grande do Sul, em sede de Apelação Cível no 70037947819, em 22 de março de 2011, pela 19. Câmara Cível, de relatoria do Desembargador Guinther Spode. Para além de meros comentários ao acórdão, pretende-se realizar apontamentos teóricos acerca da vulnerabilidade do consumidor e da sua tutela sujeito ao ordenamento jurídico brasileiro, tendo em vista a flagrante desigualdade nas relações consumeristas; a problemática central está sob a percepção da existência ou não de uma relação entre a hipervulnerabilidade do consumidor e, em especial, do consumidor idoso e o fenômeno da sociedade do hiperconsumo, bem como as suas possíveis consequências na sociedade contemporânea.

Metodologia: Os métodos de pesquisa utilizados no presente estudo são o bibliográfico e o documental. A análise realizou-se com base em trechos extraídos do acórdão elegido sobre a proteção dos consumidores. Para além de meros comentários ao acórdão, pretende-se realizar apontamentos teóricos acerca da vulnerabilidade do consumidor e da sua tutela no ordenamento jurídico brasileiro.

Resultados: A atuação dos mercados, no contexto de uma sociedade do hiperconsumo, dá-se de forma a sempre expandir seu território de dominação, a sempre incitar e induzir os consumidores a consumir de forma ilimitada. É sob essa configuração econômica e mercantilizada dos modos de viver que se dá a interação entre os principais atores da sociedade de consumo contemporânea, os fornecedores e os consumidores. Em tal cenário, evidenciam-se características de ambos os agentes que culminam em um nítido desequilíbrio dessa relação: os fornecedores possuem uma força hegemônica, seja pela situação de monopólio econômico, fático ou informacional (são os únicos e verdadeiros detentores da informação sobre produtos e serviços), e os consumidores são tidos, por essa razão, como vulneráveis. Neste contexto, baseando-se no caso objeto do acórdão, restou demonstrada a conexão entre a sociedade do hiperconsumo e os aspectos da hipervulnerabilidade do consumidor idoso, visto que, em sua posição de hegemonia o mercado, por vezes, prevalece-se indevidamente das condições existenciais especiais desses consumidores, tendo como consequência a sua massiva exploração e a flagrante desigualdade nas relações contratuais consumeristas.

Contribuições: A problemática central sobre a percepção de uma relação entre a hipervulnerabilidade do consumidor e, em especial, do consumidor idoso, bem como do fenômeno da sociedade do hiperconsumo e as suas possíveis consequências na sociedade contemporânea em função do cenário social a ser descrito. Importante esclarecer que o presente estudo utiliza-se, portanto, do contexto de uma sociedade do hiperconsumo - em que se está diante de uma mercantilização dos modos de vida - para analisar e salientar a condição de hipervulnerabilidade do consumidor idoso e a necessidade de amparo jurídico diferenciado a essa parcela da população brasileira.

Palavras-chave: consumidor idoso; hipervulnerabilidade; sociedade do hiperconsumo. 


\begin{abstract}
Objective: The purpose of this article is to analyze the decision held by the higher Court of Justice of the State of Rio Grande do Sul in Appeal No. 70037947819, on March 22, 2011, of the 19th Civil Chamber, reported by Cour of Appeals Judge Guinther Spode. In addition to the comments on the judgment, it is intended to make theoretical notes about the vulnerability of consumers and their protection subject to the Brazilian legal system, in view of the flagrant inequality in consumer relations; the central issue is the perception of the existence or not of a relationship between the hype-vulnerability of the consumer and, in particular the elderly consumer and the phenomenon of the hyper-consumption society, as well as its possible consequences in contemporary society.
\end{abstract}

Methodology: The research methods used in the present study are bibliographic and documentary. The analysis was carried out on the basis of excerpts taken from such high court decision on consumer protection. In addition to the comments on the higher court judgment, it is intended to make theoretical notes about the vulnerability of the consumer and his protection in the Brazilian legal system.

Results: The performance of the markets in the context of a hyper-consumption society occurs in such a way as to always expand its dominating territory to always incite and induce consumers to consume unlimitedly. It is under this economic and commercial configuration of the way of living that the interaction takes place between the main actors of contemporary consumer society, suppliers and consumers. In such a scenario, characteristics of both agents are evident that culminate in a clear imbalance in this relationship: suppliers have a hegemonic force due to the situation of economic, factual or informational monopoly (they are the only and true holders of information about products and services) and consumers are therefore considered vulnerable. In this context, based on the higher court decison subject case, the connection between the hyper-consumption society and the hyper-vulnerability aspects of the elderly consumer haves been demonstrated, considering its position of hegemony, the market sometimes unduly prevails from the special existential conditions of these consumers, resulting in their massive exploitation and the flagrant inequality in consumer contractual relations.

Contributions: The central issue regarding the perception of a relationship between the hyper-vulnerability of the consumer and, in particular, the elderly consumer, as well as the phenomenon of the hyper-consumption society and its possible consequences in contemporary society according to the social scenario to be described. It is important to clarify that this study uses, therefore, the context of a hyper-consumption society - in which there is a commercial of way of life - to analyze and highlight the condition of hyper-vulnerability of the elderly consumer and the need for differentiated legal support to this portion of the Brazilian population.

Keywords: elderly consumer; hyper-vulnerability; hyper-consumption society. 


\section{INTRODUÇÃO}

A pós-modernidade, em clara contradição aos tempos incrivelmente racionais e minuciosamente coordenados (ou, ao menos, assim desejava-se) da modernidade ${ }^{1}$, desdobrou-se em uma sociedade de alta complexidade, em que as relações sociais tornaram-se profundas e multifacetadas. Atualmente, assiste-se à instituição daquilo que se chama "sociedade do hiperconsumo", assim denominada por Gilles Lipovetsky como a evolução da sociedade de massa em uma sociedade de consumo altamente capitalista.

A evolução da sociedade de massa para a sociedade do hiperconsumo evidencia, além de elevação do nível mundial das práticas de consumo e sua complexidade, a imensa desigualdade entre seus atores (fornecedores e consumidores). O caso específico analisado no presente trabalho trata dessa relação de vulnerabilidade do consumidor e, em especial, de um consumidor duplamente frágil (ou de vulnerabilidade agravada): o consumidor idoso. Assim, no decorrer do presente estudo pretende-se desenvolver a correta ideia da qualificação da vulnerabilidade em hipervulnerabilidade do consumidor idoso no contexto de uma sociedade do hiperconsumo.

Para tanto, o presente trabalho tem como objeto de análise prática, o acórdão julgado em 22 de março de 2011 pela 19a․ Câmara Cível do Tribunal de Justiça do Rio Grande do Sul, de relatoria do Desembargador Guinther Spode. Para além de meros comentários ao acórdão, pretende-se realizar apontamentos teóricos acerca da vulnerabilidade do consumidor e da tutela deste sujeito no ordenamento jurídico brasileiro.

A problemática central dá-se sob a percepção de uma relação entre a hipervulnerabilidade do consumidor e, em especial, do consumidor idoso, bem como

\footnotetext{
${ }^{1}$ Zygmunt Bauman identifica a modernidade como a fase da humanidade que tentou estruturar e controlar processos que até então eram considerados contingentes e aleatórios, dando início a uma marcha rumo à certeza e a segurança: "Na fase 'sólida' inicial, a modernidade foi vivenciada como uma longa marcha rumo à ordem - aquela 'ordem' entendida como o domínio da certeza e do controle, e em particular da certeza de que os eventos até então irritantemente caprichosos seriam postos sob controle e assim permaneceriam, tornando-se, portanto, previsíveis e sujeitos ao planejamento." (BAUMAN, 2013, p. 43).
} 
do fenômeno da sociedade do hiperconsumo e as suas possíveis consequências na sociedade contemporânea. O cenário social a ser descrito - de uma sociedade do hiperconsumo - revela a necessidade de analisar-se instrumentos jurídicos que sejam capazes de configurar uma ordem normativa sensível à adequada tutela de atores vulneráveis que se encontram em certas relações, como é o caso do consumidor idoso.

Importante esclarecer que o presente estudo stiliza-se, portanto, do contexto de uma sociedade do hiperconsumo - em que se está diante de uma mercantilização dos modos de vida - para analisar e salientar a condição de hipervulnerável do consumidor idoso e a necessidade de amparo jurídico diferenciado a essa parcela da população brasileira.

$\mathrm{Na}$ primeira seção, analisa-se as circunstâncias fáticas do caso objeto do acórdão, situação em que houve a venda de uma "almofada milagrosa" à consumidora idosa por meio de contrato de crédito consignado, bem como o relatório do acórdão, de forma a viabilizar o entendimento da relação entre a sociedade do hiperconsumo e a hipervulnerabilidade do consumidor idoso.

A segunda seção ocupa-se de breve análise normativa da tutela do consumidor no ordenamento jurídico pátrio e, em específico, do consumidor idoso, que conta com a proteção outorgada pela Constituição Federal de 1988 e pelo Código de Defesa do Consumidor, textos normativos que trazem o reconhecimento da vulnerabilidade agravada desse sujeito.

A terceira e última seção apresenta a tendência de qualificação da vulnerabilidade em hipervulnerabilidade, vulnerabilidade esta agravada, explorada no contexto de uma sociedade do hiperconsumo, analisando especificamente a situação do consumidor idoso, buscando ainda relacionar esse aspecto de fragilidade agravada do consumidor de idade alentada com a sociedade do hiperconsumo.

Para a execução da presente tarefa, elegeu-se, como método de pesquisa do presente estudo o bibliográfico e documental. 


\section{RELATO DO CASO EM ANÁLISE: A VENDA DE ALMOFADAS "MILAGROSAS" PARA IDOSOS POR VENDA CONSIGNADA}

A idosa Elza Maria de Araújo Lima ajuizou ação ordinária contra Fiber Slins Comércio de Produtos Fisioterápicos (primeira demandada) e Banco Cacique (segundo demandado). Alegou a idosa que a primeira demandada, por meio de um representante comercial, foi até sua residência e ofereceu-lhe uma "Almofada Digital", de uso fitoterápico, que tinha a promessa de alívio de dores musculares e nas costas. Ressalta que o produto tinha um valor muito elevado em relação a sua renda mensal, mas que foi induzida a efetuar um empréstimo com desconto em seu benefício do INSS, perante o segundo demandado (banco), tendo a mesma efetuado a compra.

Ao perceber que o produto não funcionava da forma esperada, a requerente procurou contato com ambos os requeridos, mas não obteve êxito, tendo a instituição bancária ainda the negado acesso aos documentos que continham a informação de quem havia parcelado a compra para a autora.

Alegou a requerente ter sido ludibriada e induzida em erro, pois, na data da compra, gozava de 72 anos, além de possuir baixo grau de instrução, pleiteando indenização por danos morais e materiais causados ao seu direito de personalidade. Pleiteou ainda antecipação de tutela, para que fossem suspensos quaisquer descontos em seu benefício do INSS relativos à aquisição do produto e, no mérito, requereu a rescisão contratual estabelecida entre as partes.

$\mathrm{Na}$ sentença prolatada pelo juízo a quo, o magistrado julgou procedente a ação, cujo dispositivo possui o seguinte teor:

ISSO POSTO, afastada a preliminar arguida, julgo procedente a pretensão da autora, para: rescindir os contratos de compra e venda e financiamento entabulados entre as partes; e condenar os demandados, solidariamente, a devolverem à autora as parcelas descontadas de seu benefício previdenciário, no valor de $R \$ 24,00$ cada, corrigidas monetariamente pelo IGP-M desde a data de cada desembolso (dia de pagamento do benefício previdenciário), bem como ao pagamento do montante de $\mathrm{R} \$ 5.000,00$ (cinco mil reais), a título de danos morais, tudo acrescido de juros moratórios de $1 \%$ ao mês (art. 406 do Código Civil, c/c 161, § 1ํㅡ, do Código Tributário Nacional), devidos a partir da última citação (art. 219, "caput", do 


\begin{abstract}
Código de Processo Civil). Outrossim, por ser meramente estimativo o valor sugerido a título de danos morais, condeno os demandados a arcarem com a totalidade das custas processuais e honorários advocatícios ao patrono da parte adversa, que fixo em $15 \%$ sobre o valor atualizado da condenação, ante a natureza da causa e o trabalho exigido, observados os parâmetros do art. 20, § 3o, do Código de Processo Civil. Após o recebimento do valor da condenação, a autora deverá colocar à disposição da empresa FIBER SLINS COMÉRCIO DE PRODUTOS FISIOTERÁPICOS, a quem caberá o recolhimento no prazo de 60 dias, a almofada térmica digital objeto do negócio rescindido, com todos os seus acessórios.
\end{abstract}

Inconformado com a decisão prolatada, o Banco Cacique interpôs apelação civil, sustentando em suas razões que: a) a simples insatisfação com o produto não enseja o descumprimento da obrigação de pagar o financiamento junto à instituição financeira por parte da recorrida; b) o Banco Cacique e a Fiber Slins são empresas apartadas, não podendo a instituição financeira ser responsabilizada por um produto que a outra parte demandada comercializa; c) que, se o contrato for desfeito, a Fiber Slins deveria devolver ao banco a quantia financiada; e d) a impossibilidade de responsabilidade solidária do Banco Cacique, posto que o simples fato de ter concedido financiamento não tem o condão de torná-lo responsável, pleiteando ainda que seja minorado o valor a título de indenização moral.

Ressalta-se que a ré Fiber Slins Comércio de Produtos Fisioterápicos não recorreu da ação ordinária.

Foram apresentadas contrarrazões, oportunidade em que a autora requereu o não provimento do apelo, pleiteando, portanto, que a sentença fosse mantida para a condenação do apelado nas penas de litigância e má fé, na forma dos artigos 14, incisos I,II e III; 16, 17, incisos IV, V, VI; 18 do Código de Processo Civil.

O Tribunal de Justiça do Rio Grande do Sul, no julgamento da apelação cível interposta pelo Banco Cacique, negou provimento ao apelo e manteve a decisão proferida em sede de $1^{\circ}$ grau, em sua integralidade, por entender ter ocorrido o dano moral e material à recorrida, bem como a responsabilidade solidária dos réus e a rescisão do contrato de compra da "almofada milagrosa". O acórdão restou assim ementado:

CONSUMIDOR. AÇÃO DE INDENIZAÇÃO. VENDA A DOMICÍLIO DE 


\begin{abstract}
EQUIPAMENTO DE FISIOTERAPIA. PROMESSA DE CURA ATRAVÉS DE "ALMOFADA DIGITAL". DESCONTO DOS VALORES NO BENEFÍCIO PREVIDENCIÁRIO DA APOSENTADA. PESSOA IDOSA E DE BAIXA INSTRUÇÃO. RESCISÃO DE CONTRATO MANTIDA. RESPONSABILIDADE SOLIDÁRIA DO BANCO QUE INTERVÉM PARA VIABILIZAR O EMPRÉSTIMO E DESCONTO DAS PRESTAÇÕES. DANO MORAL CONFIGURADO. Revela-se abusiva a prática comercial de venda de produtos que se revelam inoperantes, aproveitando-se da idade e condição social do consumidor. Infringência dos art. 37, § $1^{\circ}$ e 39 , IV, CDC. Direito do consumidor ao desfazimento do contrato e o reembolso prestações que já foram pagas ou descontadas. Manifesta a responsabilidade do banco que intervém, associando-se à empresa que comercializa o produto, procedendo ao desconto na folha do aposentado. Nesses termos, a responsabilidade é solidária, por ter integrado a cadeia de fornecimento, conforme o disposto no art. $7^{\circ}$, parágrafo único, do CDC. Dano moral configurado ante o ludibrio da consumidora e a frustração da legítima expectativa desta quanto ao produto, inexistindo qualquer argumento suficiente para alterar 0 valor arbitrado ou razão para o seu redimensionamento. Apelo improvido.
\end{abstract}

Em síntese, é o relato dos fatos e do conteúdo do acórdão em estudo, que tem como objeto a tutela dos direitos do consumidor e, especialmente do consumidor idoso, que demanda uma proteção especial por parte do Estado, posto que se encontra em uma condição de vulnerabilidade agravada, matéria que será o parâmetro para os comentários do acórdão que se dá a seguir.

\title{
3 A PROTEÇÃO JURÍDICA DO CONSUMIDOR NO BRASIL COMO UM DIREITO FUNDAMENTAL E PRINCÍPIO LIMITADOR DA INICIATIVA PRIVADA
}

No presente estudo procura-se melhor compreender a disciplina da proteção jurídica do consumidor idoso no ordenamento pátrio, da forma como retratada no julgado objeto de análise, à luz dos direitos fundamentais e princípios constitucionais de proteção do consumidor.

Após o relatório processual e em suas razões de voto, o Relator do acórdão analisado, parafraseando a sentença, se manifesta da seguinte forma:

[...] Dessa forma, dúvidas não pairam acerca da abusividade da prática comercial adotada pela empresa Fiber Slins, apoiada no financiamento fornecido pela instituição financeira, que, valendo-se da vulnerabilidade 
da autora, em razão de sua idade, saúde, nível de conhecimento e condição social, sob a promessa de que o produto teria propriedades curativas para várias doenças, induziu a demandante a comprar a mercadoria. (grifo) (RIO GRANDE DO SUL, Tribunal de Justiça do Estado do Rio Grande do Sul, 2011, p. 6).

O aspecto da vulnerabilidade do consumidor muito diz respeito das intenções e objetivos de um Direito que segue afirmando um compromisso com a proteção dos indivíduos mais frágeis. No contexto de uma sociedade massificada e do hiperconsumo ${ }^{2}$, evidencia-se a desigualdade entre os atores desta sociedade (fornecedores/mercado e consumidores).

Até o século passado, o direito privado brasileiro era um direito completamente individualista, pautado nos ideais de igualdade, de liberdade contratual e de autonomia da vontade (quedam-se dúvidas quanto a adequabilidade dos termos "autonomia" e "vontade", quando se pensa em um contexto de uma sociedade majoritariamente burguesa e elitista, como era o Brasil do século XX), ideais que apresentavam somente uma função de aparência, pois, na realidade fática das relações privadas, não era isto que se observava.

Para que seja possível identificar uma mudança de paradigma no direito privado brasileiro e a inclusão de uma efetiva proteção destes sujeitos vulneráveis, imprescindível analisar os marcos legislativos da Constituição Federal de 1988 e do Código de Defesa do Consumidor.

Constituições Federais são um documento político e ideológico que refletem o pensamento jurídico da humanidade (NUNES, 2012, p. 46) e, como um instrumento de organização e regulação do Estado e da sociedade, refletem e acompanham as mudanças sociais de suas comunidades. No Brasil, da década de 60 a 80, e especialmente após a crise da ditadura militar, havia por parte da população um anseio por transformações, por uma sociedade democrática, mais justa e representativa.

Sob este contexto, firmada em um compromisso político e constitucional de uma sociedade democrática e mais sensível às fragilidades de certos agentes da

${ }^{2}$ A referência a uma sociedade do hiperconsumo é de Lipovetsky: LIPOVETSKY, 2015. 
sociedade, a Constituição Federal de 1988 trouxe, como parte da efetivação desses ideais, a proteção do consumidor como um direito fundamental (art. 5ำ, inciso XXXII) e como um princípio limitador da iniciativa privada (art. 170, V), que se fundamentam na compensação das relações de consumo, desequilibradas por natureza por fatores de vulnerabilidade, de uma parte, e de hegemonia, de outra.

Não bastasse a tutela do consumidor como um direito fundamental e como um princípio constitucional, a Constituição Federal, em seu Ato das Disposições Constitucionais Transitórias, no art. 48, definiu ainda a edição de um Código de Defesa do Consumidor, que foi editado em 1990.

O Código de Defesa do Consumidor, portanto, é legislação infraconstitucional especial às necessidades e particularidades do consumidor, sendo a maior delas a sua condição de vulnerabilidade face aos fornecedores, posto que se trata de uma relação entre desiguais: de um lado, tem-se o mercado de consumo, que conduz suas interações com hegemonia e superioridade e, do outro lado, encontra-se o consumidor, indivíduo vulnerável por natureza nesta relação, devido a sua condição fática e informacional, afastado dos processos de produção e, portanto, em situação de clara fragilidade nas relações contratuais.

Mecanismos de compensação devem ser utilizados na tutela desse indivíduo, mormente para o fim de se promover a justiça nestas relações, que são desiguais. Nesta linha, em determinado trecho de seu voto, o Relator reconheceu a aplicabilidade do art. $7^{\circ}$ do Código de Defesa do Consumidor ao caso concreto, confirmando a responsabilidade solidária da instituição bancária juntamente com a primeira demandada:

A situação narrada nos autos já é conhecida deste Tribunal, dado o grande número de casos semelhantes, tendo-se firmado entendimento de que é manifesta a responsabilidade do banco que intervém no negócio, associando-se à empresa que comercializa o produto procedendo ao desconto na folha do aposentado. Nesses termos, a responsabilidade é solidária, por ter integrado a cadeia de fornecimento, conforme o disposto no art. 7ํㅡㄹ parágrafo único, do CDC. (RIO GRANDE DO SUL, Tribunal de Justiça do Estado do Rio Grande do Sul, 2011, p. 5).

O art. 7º., parágrafo único, do Código de Defesa do Consumidor dispõe que 
"tendo mais de um autor a ofensa, todos responderão solidariamente pela reparação dos danos previstos nas normas de consumo.". Nesta perspectiva, acertada a decisão do relator no sentido de responsabilizar solidariamente a instituição financeira recorrente, posto que influiu, de forma inegável e direta, para que o contrato de crédito consignado fosse realizado, tendo em vista que, em se tratando de venda à domicílio, onde o tipo de consumidor é previamente conhecido e escolhido (no caso, o idoso), dificilmente a venda teria ocorrido de forma inversa, caso o sujeito precisasse se deslocar de sua residência até uma loja física para procurar pelo produto, chegando, muitas vezes, a inclusive desconhecer a existência da dita mercadoria.

Exemplo claro e fiel da alegação aqui exarada é o caso concreto objeto do presente estudo, em que se tem a venda induzida de forma maliciosa, tendenciosa e ludibriosa de um produto aparentemente desprovido de quaisquer das funcionalidades alegadas ("almofada digital", com a promessa de alívio de dores musculares e nas costas), valendo-se ainda os demandados dos aspectos pessoais de um consumidor sabidamente mais vulnerável - uma senhora idosa, com baixa instrução educacional e com baixa renda - para obter lucro, lucro este claramente indevido.

Situada a questão nestes moldes, imperiosa faz-se esta nova configuração de sujeitos, baseada no reconhecimento da existência de um sujeito diferente, especial, mais fraco. Este reconhecimento, como dito anteriormente, dá-se por meio da tutela do consumidor na Constituição Federal de 1988 e no Código de Defesa do Consumidor, que constitui uma concretização real do princípio da igualdade, com vistas a alçar o consumidor ao mesmo nível do fornecedor, a equilibrar as relações de consumo, possibilitando à parte mais fraca os mecanismos necessários para essa igualdade, como, por exemplo, a disponibilização de informações ao consumidor, bem como a boa-fé e a transparência que devem pautar as relações contratuais.

Por derradeiro, outro ponto a destaca-se do referido acórdão é o reconhecimento da ocorrência do dano moral. Neste sentido, a decisão: 
Deve ainda ser afastada a alegação por parte do apelante no que tange à alegada ausência da comprovação do dano moral. Cumpre salientar que os danos experimentados pelo consumidor, neste caso concreto, são daqueles que se caracterizam como danos in re ipsa, ou seja, dispensam a prova. A simples ocorrência dos fatos já suficiente a desencadear o sofrimento, a afetação moral. Assim considerando, o dever de indenizar é medida que se impõe. Tratando-se de prática ilegal, uma vez que induz o consumidor em erro, cabível a condenação por danos morais, além da devolução dos valores descontados no benefício previdenciário da autora a fim de quitar 0 bem, não existindo qualquer argumento que elida o valor arbitrado ou a razão para o seu redimensionamento. (RIO GRANDE DO SUL, Tribunal de Justiça do Estado do Rio Grande do Sul, 2011, p. 9-10).

In casu, verifica-se acertada a decisão do Tribunal quanto à condenação dos demandados por danos morais e pela devolução dos valores descontados, posto que os danos inculcados à consumidora idosa foram provenientes de uma prática incompatível com a hipervulnerabilidade da pessoa idosa, cabendo a esta, pelo que pode se extrair da decisão, uma dívida (em tese irretratável) de um produto que sequer cumpria as funcionalidades que se propunha.

Nessa esteira, correta foi a aplicação da legislação constitucional e infraconstitucional de tutela especial aos consumidores pelo Poder Judiciário, que reconheceu a vulnerabilidade da consumidora face aos fornecedores com quem contratara, a responsabilidade solidária dos demandados, bem como a sua condenação à indenização por danos morais. Isso demonstra o correto reconhecimento de que estes sujeitos estão expostos a toda a sorte de abusos e excessos cometidos pelo mercado de consumo, devendo ser tutelados de forma especial.

\section{A QUALIFICAÇÃO DA VULNERABILIDADE EM HIPERVULNERABILIDADE DO CONSUMIDOR IDOSO NO CONTEXTO DA SOCIEDADE DO HIPERCONSUMO}

No cenário de problemas descrito, evidencia-se a posição de sujeito vulnerável, ou mais frágil, que ocupa o consumidor idoso em relação ao mercado. Isto porque a sociedade do hiperconsumo caracteriza-se, para além de uma mudança nos comportamentos de seus atores principais, pela inegável hegemonia 
do sistema econômico, que exerce seu domínio sob os consumidores de uma forma preponderante e incisiva. Isso claramente evidencia a necessidade de se analisar a relação consumidor/fornecedor sob o prisma do ordenamento jurídico, no intuito de demonstrar institutos capazes de assegurar uma justa tutela à parte mais vulnerável dessa relação e, mais concretamente, instrumentos normativos específicos à tutela do consumidor idoso, que se configura como um consumidor ainda mais vulnerável.

Nesta perspectiva, a vulnerabilidade agravada (ou hipervulnerabilidade) deste indivíduo manifesta-se pelo poder hegemônico mantido pelo sistema econômico, pela concentração de capitais e de força econômica. Todo esse monopólio econômico e informacional sustentado pelo mercado culminam em um flagrante desiquilíbrio nas relações contratuais entre consumidores idosos e fornecedores.

Mas não somente: para além das questões aqui levantadas em relação ao sistema econômico e a forma hegemônica com que pauta suas relações, a hipervulnerabilidade do consumidor idoso decorre ainda das diversas condições especiais que Ihe são inerentes e que agravam essa situação de vulnerabilidade comum a todo e qualquer consumidor, posto que tais condições especiais são exploradas pelos fornecedores, o que será aqui demonstrado. Essa evidente desigualdade nessas relações contratuais demanda uma ação protetora especial do Estado para com esses sujeitos expostos a uma condição de hipervulnerabilidade.

Portanto, o reconhecimento da fragilidade especial dos consumidores idosos pelo Poder Judiciário brasileiro é ato fundamental para o justo tratamento das relações consumeristas, devendo refletir o sensível e inclusivo projeto político constitucional de 1988, que muito atentamente observou as condições especiais desse sujeito - que é mais vulnerável que os consumidores ordinários -, de forma a reestabelecer o equilíbrio nas desiguais relações entre os atores da sociedade do hiperconsumo, como é retratado no caso em análise.

Às fls. 5-6 do acórdão em comento, o relator, valendo-se da sentença proferida em primeiro grau, aduziu: 
previamente escolhido, por ser aposentado, o que garante o pagamento do negócio mediante empréstimo consignado, bem como pela forma ludibriosa usada pelos vendedores para impor a venda de uma almofada térmica digital, sabendo-se que pessoas idosas são as que mais apresentam problemas de saúde, torna evidente a prática abusiva adotada pelos demandados, pois se prevalecem das condições pessoais do consumidor, a fim de obterem êxito e lucro na venda de um produto que dificilmente seria procurado, caso fosse vendido num estabelecimento comercial. (grifo). (RIO GRANDE DO SUL, Tribunal de Justiça do Estado do Rio Grande do Sul, 2011, p. 6).

Importa ressaltar duas características relevantes da passagem acima destacada. A primeira delas diz respeito a condição de hipervulnerabilidade do consumidor idoso, ainda que não se tenha expressamente utilizado a referida terminologia, foi indiscutivelmente reconhecida: "sabendo-se que pessoas idosas são as que mais apresentam problemas de saúde, torna evidente a prática abusiva adotada pelos demandados, pois se prevalecem das condições pessoais do consumidor." (RIO GRANDE DO SUL, Tribunal de Justiça do Estado do Rio Grande do Sul, 2011, p. 6).

Cumpre ressaltar que a expressão "hipervulneráveis" surgiu, pela primeira, vez na jurisdição brasileira no Recurso Especial 586.316-MG, julgado no Superior Tribunal de Justiça. Todavia, a condição de vulnerabilidade agravada de alguns consumidores já era mencionada no Código de Defesa do Consumidor, nos artigos 37 , parágrafo $2^{\circ}$., que trata das crianças, e 39 , inciso IV, que trata da condição de fragilidade agravada dos idosos ("fraqueza [...] tendo em vista sua idade, saúde, conhecimento ou condição social), mas não sob a definição de "hipervulnerabilidade" (MARQUES; MIRAGEM, 2014, p. 200-201).

A nova terminologia foi consolidada pela jurisprudência do Superior Tribunal de Justiça, tendo a nomenclatura utilizada pelo Ministro Relator Herman Benjamin sido acatada pela doutrina.

A jurisprudência e a doutrina vêm, portanto, apontando uma tendência de qualificação da vulnerabilidade em hipervulnerabilidade de alguns consumidores, como é o caso do julgado em análise. A hipervulnerabilidade é considerada uma situação de agravamento da vulnerabilidade comum aos consumidores em geral, em razão de condições pessoais e únicas deste sujeito. Cláudia Lima Marques e Bruno 
Miragem afirmam que a hipervulnerabilidade seria a:

[...] situação social fática e objetiva de agravamento da vulnerabilidade da pessoa física consumidora, por circunstâncias pessoais aparentes ou conhecidas do fornecedor, como sua idade reduzida [...] ou idade alentada [...] ou sua situação de doente. (MARQUES; MIRAGEM, 2014, p. 201-202).

É cediço que a vulnerabilidade é princípio orientador do sistema de proteção jurídica do consumidor, consagrada no art. 4º., inciso I, do Código de Defesa do Consumidor (NISHIYAMA, 2015, p. 190). Ademais, trata-se de uma presunção legal e absoluta, ou seja, todo e qualquer sujeito que se qualifique, nos termos da lei, como consumidor, é considerado vulnerável: seja analfabeto ou doutor, seja pobre ou seja rico, seja homem ou mulher, sendo consumidor, será vulnerável (MARQUES; MIRAGEM, 2014, p. 197-198).

Neste contexto, enquanto a vulnerabilidade é categoria geral intrínseca a todos os consumidores, a hipervulnerabilidade é categoria especial e derivada da vulnerabilidade comum, exclusiva de apenas algumas categorias de sujeitos que, em razão de características pessoais, sofrem de um agravamento em sua fragilidade (MARQUES; MIRAGEM, 2014, p. 202-203).

Ressalta-se ainda que a hipervulnerabilidade tem fundamento constitucional e abarca essencialmente os vulneráveis que foram assim consagrados na Constituição Federal de 1988, quais sejam: as crianças e os adolescentes, as pessoas com deficiência e, como pode se observar do caso concreto, os idosos (NISHIYAMA, 2015, p. 196).

Denota-se, portanto, que o estado de vulnerabilidade agravada de alguns consumidores e, no caso específico, dos consumidores idosos, decorrem de características, físicas e biológicas, inerentes a essas pessoas. Tratam-se de atributos e particularidades intrínsecas às condições existenciais desses consumidores, que os colocam em uma posição de vulnerabilidade potencializada:

Características físicas e biológicas fazem com que a capacidade dos idosos seja diminuída, o raciocínio seja afetado pela debilidade do cérebro, redução da vitalidade do coração, perda de capacidade respiratória pela redução da força muscular do pulmão, diminuição da acuidade visual. Isso 
reflete em um cenário pessoal complexo e digno de atenção. Essas alterações abalam física e emocionalmente as pessoas idosas, tornando-as vulneráveis física, psíquica e socialmente. (grifo) (PINHEIRO, DETROZ, 2012, p. 136-137).

Desta maneira, inegável a condição de hipervulnerável dos consumidores idosos, devido a condição biológica e natural de envelhecimento a que todos os seres humanos estão expostos, apresentando um quadro especial de agravamento da vulnerabilidade comum aos consumidores em geral.

Tal situação é latente no caso analisado, em que a recorrida era pessoa idosa, de baixa instrução e baixa renda. A hipervulnerabilidade da consumidora idosa resta evidente no caso analisado, pelo que se pode extrair do acórdão, justamente porque as suas condições pessoais (de idade alentada, baixa instrução e baixa renda), foram decisivas e exploradas em tais circunstâncias, tendo sido induzida a contratar crédito consignado para a compra de um produto completamente inútil às funções que se propunha cumprir.

A segunda característica relevante a ser analisada na passagem extraída do acórdão diz respeito a conduta voraz do mercado, que muito tem à ver com as características da sociedade do hiperconsumo: "onde o consumidor é previamente escolhido, por ser aposentado, o que garante o pagamento do negócio mediante empréstimo consignado, bem como pela forma ludibriosa usada pelos vendedores para impor a venda de uma almofada térmica digital, sabendo-se que pessoas idosas são as que mais apresentam problemas de saúde" (RIO GRANDE DO SUL, Tribunal de Justiça do Estado do Rio Grande do Sul, 2011, p. 6).

Considerando-se o conjunto de argumentos apresentados neste trecho, incontestável é a conduta impetuosa do mercado na sociedade contemporânea, que pauta o seu exercício no crescimento ilimitado do consumo, incitando e estimulando este setor, com vistas a expandir a sua área de dominação.

Gilles Lipovetsky denomina a sociedade do hiperconsumo como uma sociedade em que "todas as esferas da vida social e individual se encontram, de uma forma ou de outra, reorganizadas segundo os princípios da ordem consumista. " (LIPOVETSKY, 2015, p. 109). Trata-se da expansão indefinida da esfera econômica, 
em que os agentes produtores do mercado de consumo dirigem a sua produção com vistas a sempre a ampliar o consumo.

Infelizmente, alguns fornecedores utilizam-se de técnicas e meios desleais e ilegais para atingir essa meta. É o caso do julgado que se analisa no presente estudo. Os fornecedores elegeram a recorrida, pois sabiam da sua condição especial de consumidor (pessoa idosa, sem instrução e de baixa renda, hipervulnerável), com a certeza de que obteriam vantagem desse indivíduo, visto que a venda foi realizada mediante crédito consignado, que é, em tese irretratável, por um produto no mínimo questionável ("almofada digital") e que, muito provavelmente, sob outras condições de venda (pessoa não idosa, que possua instrução e boa renda) não teria sido efetuada.

Sob semelhante contexto, outro ponto a se olhar, com cautela, no referido acórdão diz respeito a exploração e 0 abuso massificados ${ }^{3}$ do consumidor pelo mercado que, no caso concreto, consubstancia-se pelo ajuizamento de diversas demandas iguais a da autora, o que evidencia o contexto de uma sociedade do hiperconsumo. O relator assim aduziu: "A situação narrada nos autos já é conhecida deste Tribunal, dado o grande número de casos semelhantes (...)." (RIO GRANDE DO SUL, Tribunal de Justiça do Estado do Rio Grande do Sul, 2011, p. 5).

Tal alegação tem o condão de reafirmar a situação de hegemonia e a influência do mercado de consumo na sociedade do hiperconsumo, que muitas vezes se vale da sua nítida força e da latente vulnerabilidade do consumidor para expandir o crescimento econômico, que, nestes moldes, não pode ser acatado.

In casu, verifica-se que os fornecedores abusaram da condição de hipervulnerabilidade da autora, valendo-se dessa fragilidade e de sua posição de superioridade para pactuar contrato de crédito consignado pela venda de um produto que não funciona, o que lhes daria a certeza de receber o pagamento, posto que, nesta modalidade, os descontos são realizados diretamente na folha de

\footnotetext{
${ }^{3}$ Foram ajuizadas mais de 60 demandas no Estado do Rio Grande do sul sobre casos de venda de "almofadas milagrosas" para idosos por crédito consignado, veja-se algumas: ApCivel n. 70057622755, ApCivel n. 70060508769, ApCivel n.70063086722, ApCivel n. 70058995572, ApCivel n. 70061056768, ApCivel n. 70056467921, ApCivel n. 70057805434, ApCivel n. 70056585508, ApCivel n. 70055454516, ApCivel n. 70046777033, ApCivel n. 70053491262, ApCivel n. 70053346425 , ApCivel n. 70043969385.
} 
pagamento do idoso.

Resta nítido, diante do que foi exposto nos trechos analisados do acórdão, que adequada foi a decisão do Tribunal de Justiça do Rio Grande do Sul, tendo em vista que, não somente reconheceu a situação de hipervulnerabilidade da autora e a responsabilidade solidária dos demandados, mas também deliberou em favor da condenação ao pagamento de indenização por danos morais.

Não restam dúvidas de que o julgamento em análise transparece a sensibilidade jurídica inculcada na Constituição Federal de 1988 e no Código de Defesa do Consumidor quanto à condição de hipervulnerabilidade do consumidor idoso, prática esta fundamental para a efetivação da igualdade nas relações entre atores de uma sociedade do hiperconsumo, que, por natureza, são desequilibradas.

\section{CONCLUSÃO}

A atuação dos mercados, no contexto de uma sociedade do hiperconsumo, dá-se de forma a sempre expandir seu território de dominação, a sempre incitar e induzir os consumidores a consumir de forma ilimitada. É sob essa configuração econômica e mercantilizada dos modos de viver que se dá a interação entre os principais atores da sociedade de consumo contemporânea, os fornecedores e os consumidores.

Em tal cenário, evidenciam-se características de ambos os agentes que culminam em um nítido desequilíbrio dessa relação: os fornecedores possuem uma força hegemônica, seja pela situação de monopólio econômico, fático ou informacional (são os únicos e verdadeiros detentores da informação sobre produtos e serviços), e os consumidores são tidos, por essa razão, como vulneráveis.

Neste contexto, baseando-se no caso objeto do acórdão, restou demonstrada a conexão entre a sociedade do hiperconsumo e os aspectos da hipervulnerabilidade do consumidor idoso, visto que, em sua posição de hegemonia o mercado, por vezes, prevalece-se indevidamente das condições existenciais especiais desses consumidores, tendo como consequência a sua massiva 
exploração e a flagrante desigualdade nas relações contratuais consumeristas.

Verificou-se, ainda, que a proteção do direito do consumidor, outorgada pela Constituição Federal de 1988 e pelo Código de Defesa do Consumidor, fez-se efetiva no caso em comento, pelo reconhecimento da responsabilidade solidária dos réus, da hipervulnerabilidade da consumidora idosa, da ocorrência do dano moral e da rescisão dos contratos de compra e venda entabulado entre as partes, aplicando ao caso concreto uma efetiva tutela dos mais vulneráveis.

Desta feita, a decisão do Tribunal do Estado do Rio Grande do Sul, ao negar o apelo do banco recorrente e ao manter a decisão de $1^{\circ}$. grau em sua integralidade, fez jus à tutela do consumidor e, em específico, da consumidora idosa, reconhecendo a sua hipervulnerabilidade e concedendo-a o devido tratamento legal de proteção outorgado pela Constituição Federal de 1988 e pelo Código de Defesa do Consumidor, institutos normativos que implementaram um compromisso mais solidário e um objetivo de tutela especial a certos grupos diferenciados, em razão de suas condições extraordinárias de vulnerabilidade.

\section{REFERÊNCIAS}

BAUMAN, Zygmunt. Danos colaterais: desigualdades sociais numa era global. Rio de Janeiro: Zahar, 2013.

BRASIL, Constituição da Republica Federativa do Brasil de 1988. Disponível em: <http://www.planalto.gov.br/ccivil_03/constituicao/constituicaocompilado.htm> Acesso em: 27 de março de $201 \overline{8}$.

Lei n. 8.078, de 11 de setembro de 1990. Código de Defesa do Consumidor. Disponível em: <http://www.planalto.gov.br/ccivil_03/leis/L8078.htm> Acesso em: 27 de março de 2018.

LIPOVETSKY, Gilles. A felicidade paradoxal:ensaio sobre a sociedade do hiperconsumo. [2⿳亠丷⿵冂⿱⺊口灬 reimp]. Extra-coleção. 118 - Lisboa : Edições 70, 2015.

NISHIYAMA, Adolfo Mamoru. A proteção do consumidor na Constituição Federal de 1988: análise da vulnerabilidade e da hipervulnerabilidade do consumidor. 2015. Disponível em: <http://portaldeperiodicos.unisul.br/index.php/U_Fato_Direito/article/view/2828/2001> 
Acesso em: 27 de março de 2018.

MARQUES, Claudia Lima; MIRAGEM, Bruno. O novo direito privado e a proteção dos vulneráveis. 2. ed. rev., atual. e ampl. São Paulo : Revista dos Tribunais, 2014.

NUNES, Luis Antonio Rizzatto. Curso de direito do consumidor. 7. ed. rev. e atual. São Paulo: Saraiva, 2012.

PINHEIRO, Rosalice Fidalgo; DETROZ, Derlayne. A hipervulnerabilidade e os direitos fundamentais do consumidor idoso no direito brasileiro. 2012. Disponível em: <https://bdjur.stj.jus.br/jspui/handle/2011/72701> Acesso em: 27 de março de 2018.

RIO GRANDE DO SUL, Tribunal de Justiça do Estado do Rio Grande do Sul. Apelação Cível n. 70037947819. Disponível em: <http://www.tjrs.jus.br> Acesso em: 27 março de 2018. 